\title{
Poverty In The United States: A Continuing And Growing Problem
}

Berch Haroian, (E-mail: haroianb@wpunj.edu), William Paterson University

Elizabeth C. Ekmekjian, (E-mail: ekmekjiane@wpunj.edu), William Paterson University Elias C. Grivoyannis, (E-mail: grivoyan@yu.edu), Yeshiva University

\begin{abstract}
In recent years, the ability to deal with the problem of poverty in the US, in light of the new "Federalism," is an area of interest to scholars. The poverty rate over the past 50 years has fluctuated from a high of 22.4\% in 1959 to a low of $11.1 \%$ in 1973. Under George Bush's presidency, we again see an increase in the poverty rate to $12.7 \%$ in 2004. This paper provides an overview of poverty data for the $21^{\text {st }}$ century, by region, race and age. A discussion and comparison of median household income follows. Facts and figures are then provided/compared, tying in health care issues to income levels and citizenship/ethnicity. A brief introduction of the various attempts over the past years by the federal government to reduce the proportion of the American population that falls below the poverty line follows. This section merely provides a listing of programs designed to satisfy social and equity considerations. This paper does not provide the reader with the impact of these programs on the economy; a brief mention is provided to generate further thought and discussion. The paper concludes with a summary of key elements of the above issues. The sole purpose is to provide an overview of historical data as concerns poverty, median household income and health insurance coverage. The ability to deal with the problem of poverty in the $U S$, is left for another paper.
\end{abstract}

\section{BACKGROUND}

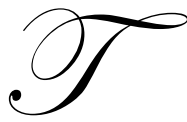

he United States (US) determines the official poverty rate using poverty thresholds issued by the Census bureau. These thresholds represent the minimal cash required to survive, broken down by thresholds for "various groups," e.g. single individuals under 65 years, single individuals 65 years \& older, etc. For example, in 2004, the poverty thresholds issued by the Census bureau for single persons under 65 years was $\$ 9,827$, for single persons 65 years and older, the threshold was $\$ 9,060$. (Compare this with real median household income during the same time period of $\$ 44,389$. See discussion of Real Median Household Income that follows.)

Over the last fifty years, the percentage of Americans with income below the poverty threshold ("poverty rate") peaked in the late 1950 's at $22.4 \%$ or 39.5 million individuals ("number in poverty"). These figures declined steadily throughout the 1960's and early 1970's, reaching a low of $11.1 \%$ or 22.9 million in 1973. Over the next decade, the poverty rate began to rise again reaching $15.2 \%$ or 35.3 million in 1983 . Throughout the years that followed, the rate stayed high and then began to decline reaching $11.3 \%$ in the year 2000. Since then it has risen slightly in each and every year reaching $12.7 \%$ in 2004. (See Figure 2 below.) 
Figure 2

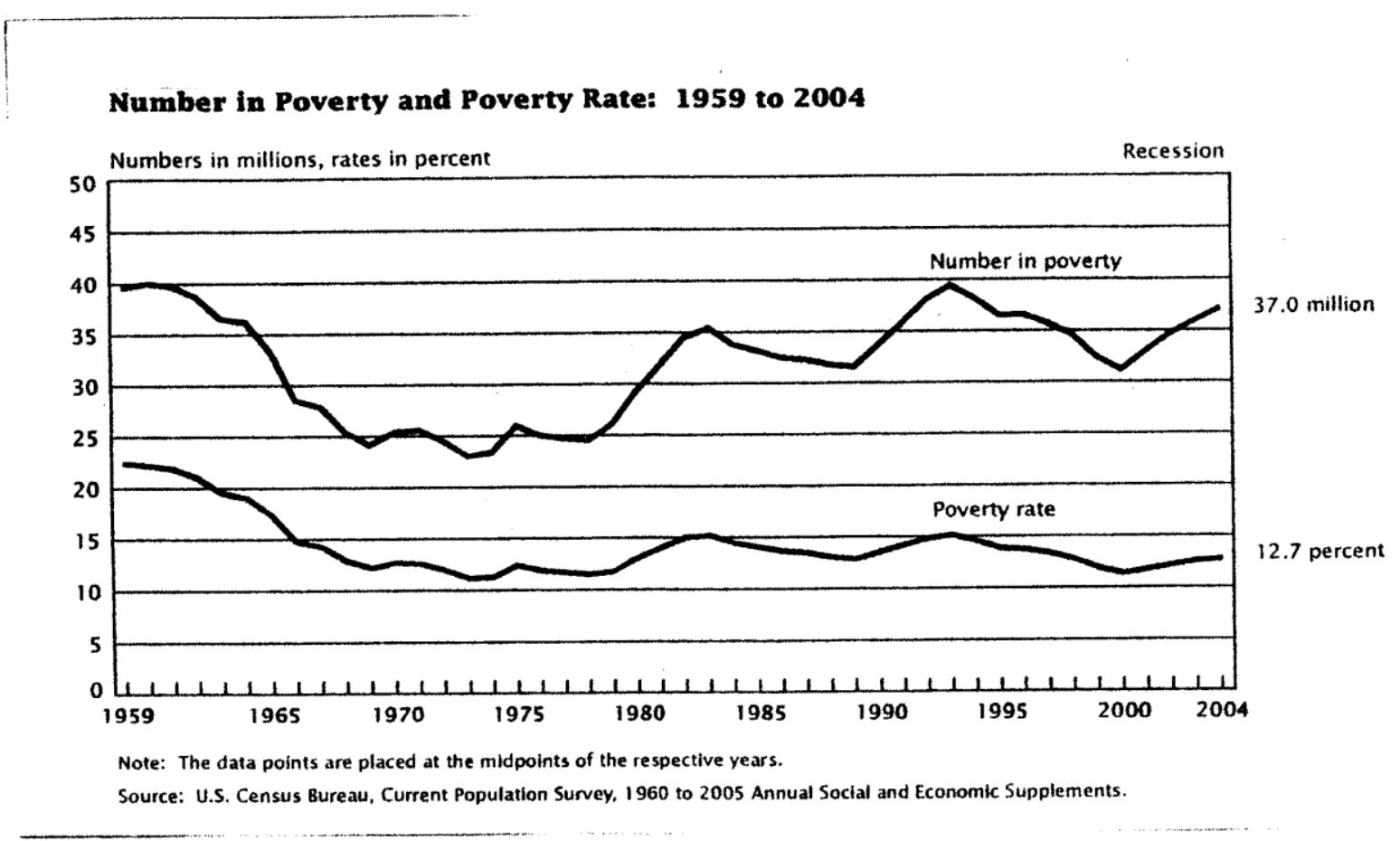

This paper provides the reader with statistical data of the US poverty rate and number in poverty focusing on facts and figures in the early twenty-first century, illustrating differences between the following characteristics: region, ethnicity and age - 65 years and older.

\section{RECENT STATISTICAL DATA}

\section{A Comparison Of Poverty Rates Between 2003 And 2004}

The official poverty rate in 2004 was $12.7 \%$ up from $12.5 \%$ in 2003 . This represents an increase of 1.1 million people to a total of 37 million in 2004.

\section{Regional Variations}

A review of poverty by regions showed that the Midwest was the only region to show an increase in both the number in poverty and the poverty rate. In $200310.7 \%$ or 6.9 million people met the criteria; in 2004 the rate and number and rate had risen to $11.6 \%$ and 7.6 million respectively. The remaining three geographic areas remained unchanged between 2003 and 2004: Northeast - 11.6\%, South - 14.1\% (highest rate per region); and West. $-12.6 \%$.

\section{Ethnicity}

During this time period, poverty rates for Blacks and Hispanics exceeded the national average. In 2004 $24.7 \%$ of Blacks and $21.9 \%$ of Hispanics were poor compared to $8.6 \%$ of Whites and $9.8 \%$ of Asians. While Whites were lower than for any racial grouping, both the poverty rate and the number in poverty increased between 2003 and 2004 from $8.2 \%$ and 15.9 million; to $8.6 \%$ and 16.9 million in 2004 . 
Age

Figure 3 presents data as to the age distribution of the poverty population. In 2004 both the poverty rate and the number in poverty for people, age 18 to 64 increased to $11.3 \%$ and 20.5 million, up from $10.8 \%$ and 19.4 million in 2003 .

A surprising finding was that although the number of seniors aged 65 and older remained unchanged between 2003 and 2004 at 3.5 million, their poverty rate declined from $10.2 \%$ to $9.8 \%$ in 2004 . This decline may have been due, in part, to the indexing of Social Security benefits.

\section{Figure 3}

\section{Poverty Rates by Age: 1959 to 2004}

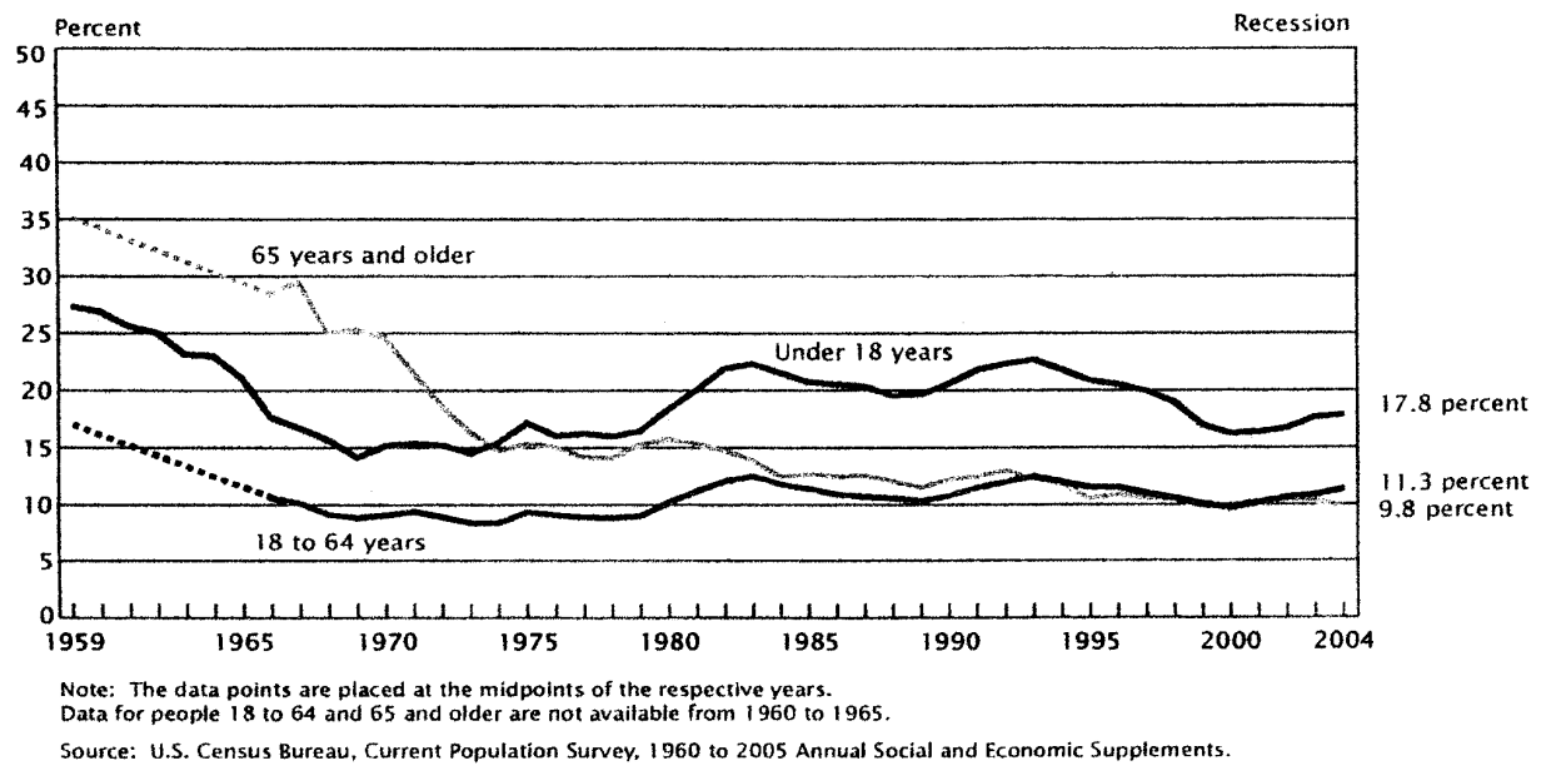

\section{Ratio Of Income To Poverty Levels}

Table 1 presents the number and percentage of people within three ranges of "income to poverty ratios:" a) those below $50 \%$ of poverty; b) those at or above $50 \%$ but below $100 \%$ of poverty; and c) those at or above their threshold but below $125 \%$ of poverty.

In 2004 the number of people with income below one half of their poverty threshold was 15.6 million, unchanged from 2003. They represented $5.4 \%$ of the total population and $42.3 \%$ of the poverty population; both rates were unchanged from 2003 . For those between $50 \%$ but at least $100 \%$ of their thresholds, their percentage and number increased from $7.2 \%$ and 20.6 million to $7.4 \%$ and 21.4 million between 2003 and 2004. For the last category, those at $125 \%$ of their threshold, the percentage and number remained unchanged in 2004 at $4.4 \%$ and 12.7 million from 2003.

For the 65 and older cohort, $2.6 \%$ were below 50 percent, compared with $5.4 \%$ for all people, while $7.2 \%$ were above 50 percent and below 100 percent of their thresholds compared to $7.4 \%$ for all people. Lastly, those in this cohort who were below $125 \%$ of poverty was $6.7 \%$ compared with 4.4 percent for all people. 
Table 1

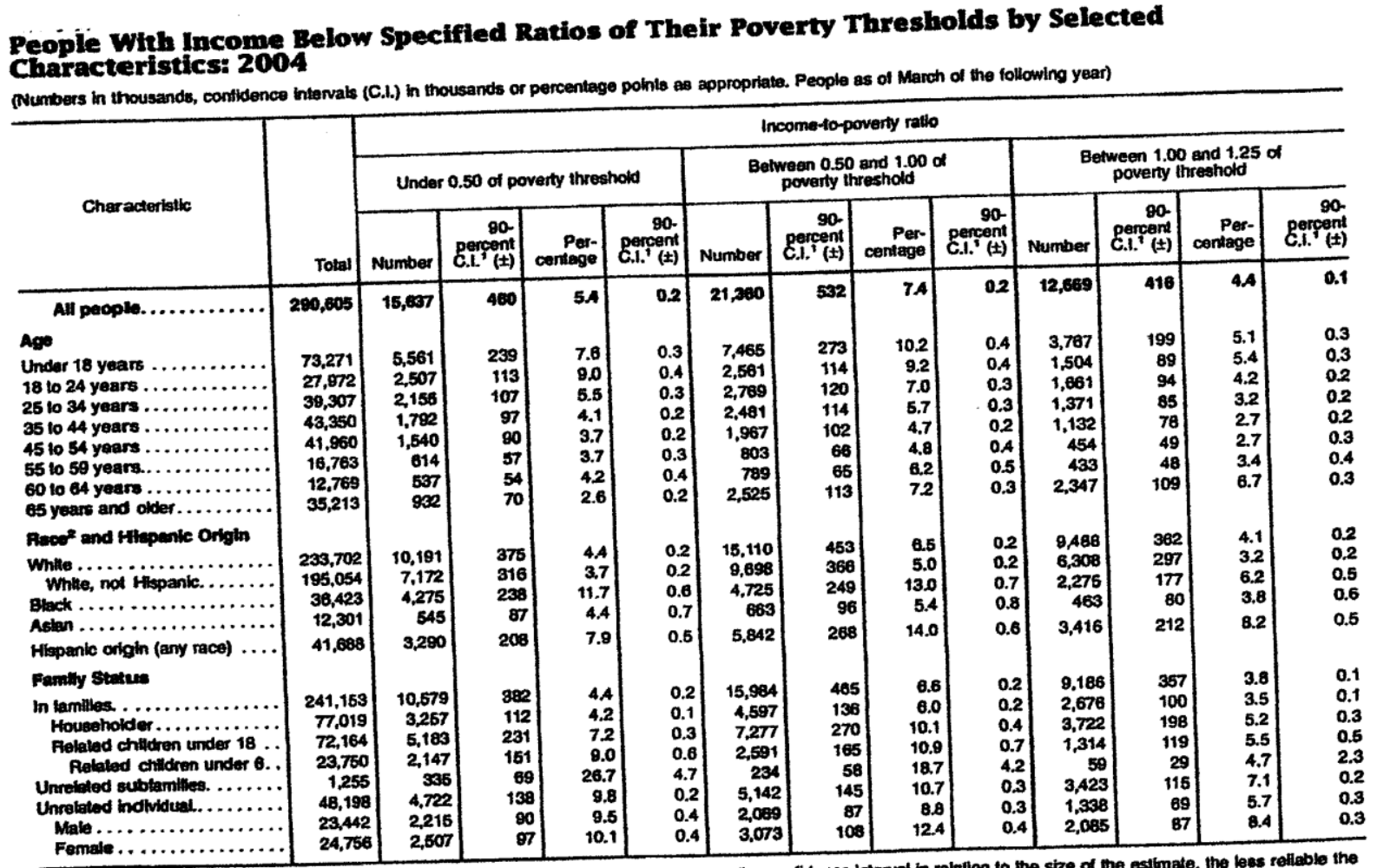

'A 90-percent confidence interval is a measure of en estimale's vartabliny. The larger the confidence intervat in relation to the size of the estimate, the less reflable the

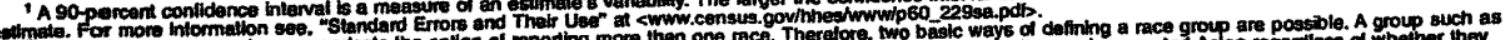

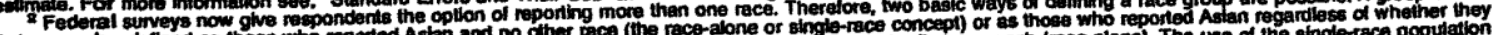

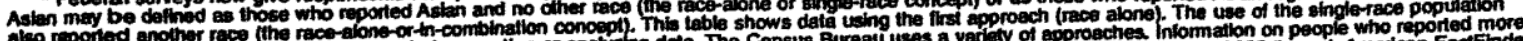

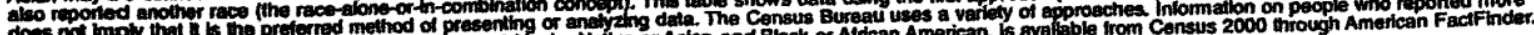

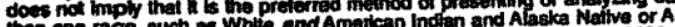
than one race, such as While and Amo in Ceneus 2000.

Note: Detalls may nol sum to totals becaues of rounding.

Source: U.S. Ceners Bureau, Current Population Survey, 2005 Annual Soctal and Economic Supplement.

\section{REAL MEDIAN HOUSEHOLD INCOME}

Median household income (MHI) can be defined as the middle value of how much people make or family income. Real median household income (RMHI) is household income adjusted for inflation. RMHI showed no change between 2003 and 2004 and was $\$ 44,389$ in 2004. (See Figure 1 below.) This was up by more than 30\% compared to the 1967 figure, $\$ 34,950$. RMHI breakdown between the following ethnic groups is noted: Black households had the lowest RMHI - \$30,134; Hispanics - \$34,241; Whites - \$48,977; while Asians had the highest household income at $\$ 57,518$. 


\section{Figure 1}

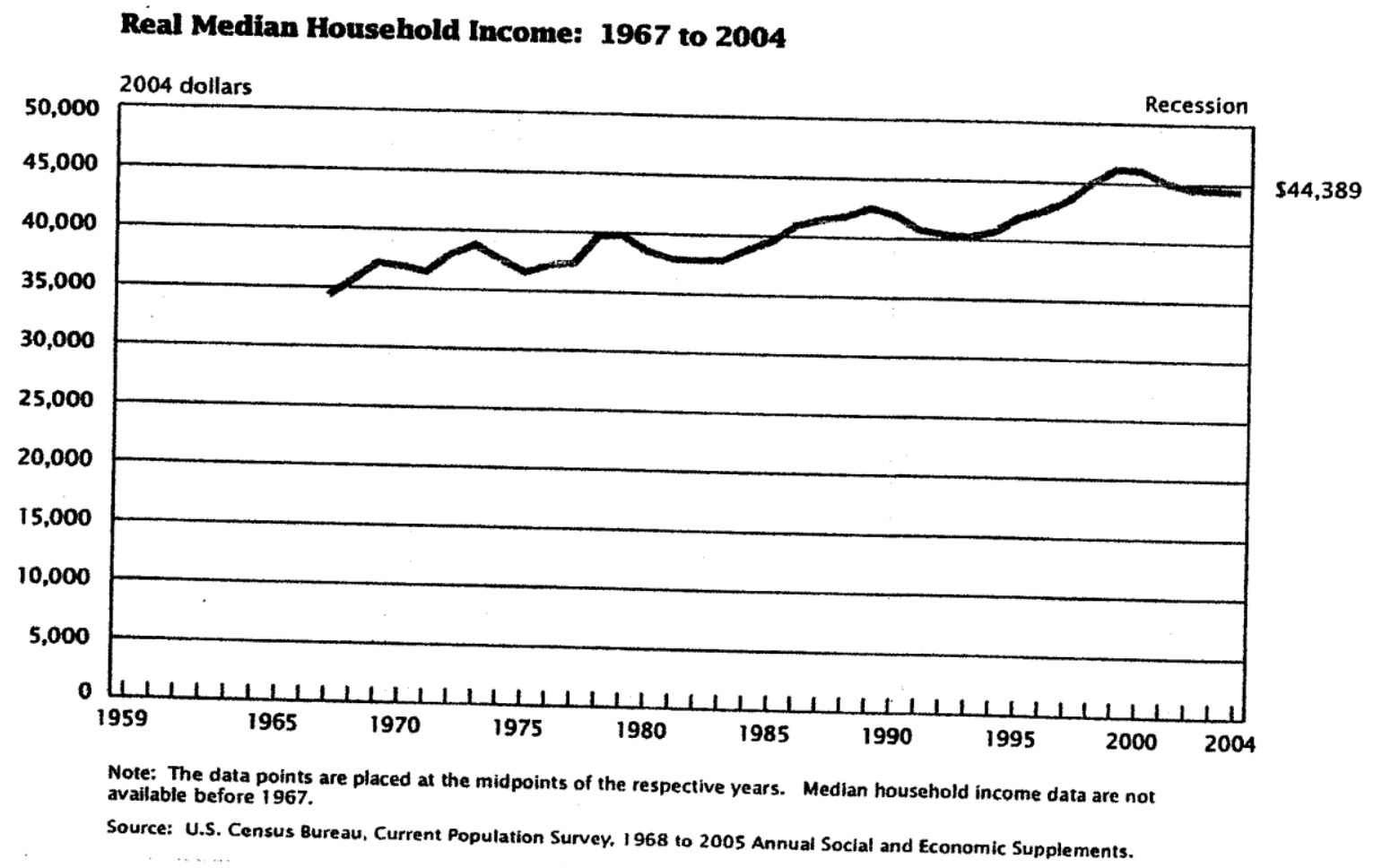

Table 6 below compares race, age, median income and real income changes between 2001 and 2006. Interestingly enough, except for Blacks, all ethnic categories age 65+ showed a decrease in absolute dollars! Compare this with all ethnic categories (disregarding age), showing an increase in absolute dollars. However, when the real income change is computed (adjusted for inflation), all showed a net loss. This real income loss was most pronounced for Blacks with a loss of $-3.4 \%$, followed by Hispanics with a decline of $-1.5 \%$, and Whites, which showed the smallest decline at $-1.4 \%$.

\section{Comparison By Age}

As discussed above, individuals age 65 and older have seen a decline in MHI. In addition, MHI of these senior citizens is drastically less than those under age 65. For example, for all races, the $2006 \mathrm{MHI}$ was $\$ 41,990$ or $\$ 18,907$ greater than senior citizens. Blacks age $65+$ trailed all other ethnic groups with respect to MHI - \$16,761 in 2001 and $\$ 16,824$ in 2006. Compare these figures to those for Whites: $\$ 23,769$ and $\$ 23,639$ for Whites over 65 in 2001 and 2006 respectively.

The decline in real income in 2006 shows Hispanics age 65+ having the lowest median income in both real and absolute terms at $\$ 16,551$. The reason for this is unclear at this time but may be due to the influence of the "illegal immigrant debate" taking place as employers and immigrants try to show their integration into the society by better reporting. At any rate this remains an area for further exploration at a later date. 
Table 6

Median Income Comparison

2001 And 2006

By Race And Age For Those 65 And Older

\begin{tabular}{llll}
\hline Category & $\mathbf{2 0 0 1}$ & $\underline{\mathbf{2 0 0 6}}$ & $\begin{array}{c}\text { \%Change In } \\
\text { Real Income }\end{array}$ \\
All Races & $\$ 42,228$ & $\$ 41,990$ & -2.2 \\
$65+$ & 23,118 & 23,083 & -2.6 \\
White-All & $\$ 44,517$ & 46,951 & -1.4 \\
$65+$ & 23,769 & 23,639 & -2.2 \\
Black-All & $\$ 29,470$ & 29,667 & -3.4 \\
$65+$ & 16,761 & 16,824 & -3.1 \\
Hispanic-All & & & -1.5 \\
$65+$ & $\$ 33,565$ & 33,168 & -0.8
\end{tabular}

Source: Median income of households by selected characteristics; US population survey, US Census Bureau selected years 20012006

\section{THE UNINSURED}

No discussion of poverty would be complete without some discussion of the population that lacks health care insurance. In 2006 some 46.6 million people or $15.9 \%$ of the population lacked insurance. Some $13.4 \%$ of native born residents were uninsured while $17.9 \%$ of naturalized citizens were uninsured. At least $43.6 \%$ of noncitizens and $43.6 \%$ of Hispanics were also uninsured, compared to $19.6 \%$ of Blacks and $15 \%$ of Whites.

There was a clear correlation between income levels and health care insurance for 2007. The highest proportion of those uninsured, $24.4 \%$, earned less than $\$ 25,000$ a year, while $20.6 \%$ of those with incomes between $\$ 25,000$ and $\$ 50,000$ were uninsured. The cohort with incomes between $\$ 50,000$ and $\$ 75,000$ only had $14 \%$ uninsured, while those with incomes over $\$ 75,000$, had an even lower number of $8.5 \%$. Regardless of income, $72 \%$ of the 46.6 million people without health care between the ages of 18 to 64 reported working either full or part time during the prior year (2006).

\section{GOVERNMENT ASSISTANCE FOR THE POOR}

Over the past thirty years, various attempts have been made by the federal government to reduce the proportion of the American population that falls below the poverty line. These measures include programs such as Medicaid, Medicare, social security, drug benefit for seniors and food stamps. In addition, certain provisions of the Federal tax law, such as the Earned Income Credit and the Credit for the Elderly and Disabled, have been designed to help control the economy, and satisfy social and equity considerations. This paper does not provide the reader with the impact of these programs on the economy; a brief mention is provided to generate further thought and discussion. The ability to deal with the problem of poverty in the US, is left for another paper.

\section{SUMMARY AND CONCLUSIONS}

After a decade long decline, the number and proportion of the American population at the poverty level has started to increase. Racial patterns remain consistent with Blacks and Hispanics exceeding the national average (as compared to Whites and Asians). Median income comparisons by ethnic group follow the poverty rate statistics: the White population had the highest median income and the lowest relative percentage rate and the Black population trailed behind both Whites and Hispanics. Despite an increase in absolute dollar income, real income for all three groups declined between 2001 and 2006. 
Since the year 2000, the US has seen an increase in various Federal Programs to aid the impoverished ranging from tax credits (the earned income credit, credit for elderly and disabled, etc.), to a drug benefit for seniors. In addition, for seniors $65+$, the indexing of social security seems to have been beneficial as both their proportion in poverty and absolute numbers have seen a consistent decline over the last twenty five years. Unanswered is what impact the rapidly retiring baby boomers will have on these numbers.

\section{BIBLIOGRAPHY}

1. US Census Bureau, Current Population Reports: Income, Poverty and Health Insurance Coverage in the United States, 2004

2. US Census Bureau, Current Population Survey, Money Income by Race and Age, March 2002

3. US Census Bureau Current Population Survey, Money Income by Race and Age, March 2006

4. US Census Bureau, Annual Demographic Survey of Money Income by Race, Region, 1997

5. University of Michigan, National Poverty Center, Poverty facts, 2006

6. USA Today, Report on the Uninsured March 15, 2007

\section{NOTES}


NOTES 